\title{
Group Virtues: No Great Leap Forward with Collectivism
}

\author{
Sean Cordell ${ }^{1}$
}

Published online: 7 January 2016

(c) The Author(s) 2016. This article is published with open access at Springerlink.com

\begin{abstract}
A body of work in ethics and epistemology has advanced a collectivist view of virtues. Collectivism holds that some social groups can be subjects in themselves which can possess attributes such as agency or responsibility. Collectivism about virtues holds that virtues (and vices) are among those attributes. By focusing on two different accounts, I argue that the collectivist virtue project has limited prospects. On one such interpretation of institutional virtues, virtue-like features of the social collective are explained by particular group-oriented features of individual role-bearers that are elicited by institutional structures or goals. On another account of groups as moral agents unbound by formal institutional constraints, to the extent that group characteristics meet the collectivist requirement, they fail to stand up as virtues in the substantive sense of a character trait. These two positions' respective drawbacks and insights support a non-collectivist conclusion: Where there is a substantive virtue of some social group, it consists only in certain group-specific attitudes and motives of individuals qua members of that group. I end by outlining some risks in adopting collectivism about virtues as an explanatory or normative doctrine, and suggesting that we can abandon it without embracing an equally undesirable individualism in virtue theory.
\end{abstract}

Keywords Virtues · Vices · Social Groups · Institutions · Collectivism

Sean Cordell

Sean.Cordell@open.ac.uk

1 The Open University in the East Midlands, Clarendon Park, Clumber Avenue, Sherwood Rise, Nottingham NG5 1AH, UK 


\section{Introduction}

Suppose we were to recognize a mountain rescue team for its courage. Could we be ascribing the virtue of courage to the team in its own right, where 'team courage' cannot be adequately explained just by saying things about its individual members? A body of work in ethics and epistemology has advanced a collectivist view which claims that in some cases we can and should make this kind of ascription (Smith 1982; Beggs 2003; Lahroodi 2007; Sandin 2007; Fricker 2010; Ziv 2012). Collectivism ${ }^{1}$ holds that some social groups can be subjects in themselves which can possess attributes such as agency or responsibility (French 1979; Graham 2002; Miller and Mäkelä 2005; Isaacs 2006; Sheehy 2007). Collectivism about virtues holds that virtues (and vices) ${ }^{2}$ are among those attributes. A commitment of the general view is that some standardly individual attributes have collective counterparts, and that these are similar enough to play the same role at both the collective and individual levels. Some, for example, have argued that there are genuine collective agents which can be held responsible, blameworthy or praiseworthy for their actions in the same way as individual agents can. ${ }^{3}$ Likewise, on a collectivist view, virtues of social groups must be numerically distinct from but qualitatively akin to virtues or vices of individuals. They need to be something other than shorthand for aggregations or effects of individuals' character traits, but also something like them: something more substantive than, say, metaphorical traits which we might attribute to non-persons ('fickle fate', 'the cruel sea').

A successful defence of collectivist virtues would establish a deep similarity between individual persons' character traits and characteristics of certain social groups, thus bolstering the view that there can be enduring group agents. It could also open up possibilities for a range of virtue-centred approaches to social and political philosophy, ${ }^{4}$ and support an evaluative shift in focus, from morally or epistemically ${ }^{5}$ praiseworthy and blameworthy characteristics of the individual to those of social groups. By focusing on two such defences, I will argue that the prospects for the collectivist virtue project are severely limited. In short, one account gives us virtue-like features that are not collectivist, while another gives us collectivist features that are not virtues in the substantive sense. On the first account, the purported virtues of the institutionally bound social group turn out to be best explained by group-oriented features of individual members, albeit features that are elicited by the goals and structures of the institutions of which they are a part. On the second account which treats less formally bound social groups as moral agents, to the extent that a group characteristic meets the collectivist requirement, it fails to

\footnotetext{
1 I follow Keith Graham (2002) in using the term 'collectivism' in this way.

${ }^{2}$ I assume throughout that insofar as there could be collective virtues there could be collective vices.

3 See also Huebner (2011) for a defence of collective emotions.

4 Michael Slote has perhaps been the most ambitious in this respect, claiming that 'the laws, customs, and institutions of a given society are, as it were, the actions of that society-they reflect or express the motives (though also the knowledge) of the social group in something like the way actions express an agent's motives (and knowledge)' (Slote 2001, p. 99).

5 See Zagzebski (2008).
} 
stand up as a virtue in the substantive sense. These two different positions may not exhaust the possibilities for a group virtue theory per se, but I will argue that their respective drawbacks and insights support the following non-collectivist interpretation of social group virtues. Where there is a substantive virtue of some social group, it consists only in certain group-specific attitudes and motives of individuals qua members of that group. In this non-collectivist sense mountain-rescue-team courage can be possessed and evinced by team members in the specific context of the team and its activities. But the rescue-team cannot possess a substantive virtue in the collectivist sense, as there is no 'team-courage' that does not consist in individual members' team oriented courage. I end by considering a further risk in adopting the collectivist virtue stance, and suggesting that we can abandon it without embracing an equally undesirable individualism in virtue theory.

\section{First Account: Institutional Virtues}

Miranda Fricker's collectivist account of virtues focuses on social institutions as sets of individuals grouped and bound by institutional rules, norms or procedures. In this context she explains how her example statement 'the jury is fair-minded' could be interpreted as saying: (1) that the individual jurors are each exhibiting fairminded characteristics; (2) that the jury as a social collective is displaying fairmindedness; or (3) that the system of trial by jury is a fair one - thus referring to procedural and formal features (Fricker 2010, p. 235).

Leaving aside (3) for now and focusing on (1) and 2), the first way of seeing things is the summativist view, on which a group or group characteristic is the aggregate sum of that same characteristic in individual members. Fricker states that:

Summativism does not work as a general account of group features, for there can be cases where a group possesses a feature that few or even none of its component individuals possess (so individual possession of the feature is not necessary); and there can be cases where the group lacks a feature even though it is possessed by many or even all of the component individuals (so individual possession of the feature is not sufficient) (Fricker 2010, p. 237).

View (2) encompasses the anti-summativist view on which a group is in some sense more (or other) than the sum of its parts. ${ }^{6}$ Fricker starts her collectivist account from this anti-summativist position and further illustrates some different ways in which a collective characteristic can be instantiated, using three examples.

\footnotetext{
${ }^{6}$ Note that whilst the collectivist would agree here that a group is in some sense more (or other) than the sum of its parts, they need not prioritize the value of the collective over the individual. As Graham notes: 'it would be perfectly plausible to hold that a society was distinct from individuals while holding that it was not superior, or that its superiority was at best problematic, or that it was superior in certain ways which needed to be specified but inferior in other ways which also needed to be specified' (Graham 2002, p. 3).
} 
(i) An administrative church committee whose members, as individuals, are open-minded about gay rights but who collectively, in the context of the church committee, exhibit close-mindedness about gay rights.

(ii) An amateur dramatics society committee whose members, as individuals, may not care much about the society's prospects, but who nevertheless qua committee members are jointly wholeheartedly committed to seeing it survive and flourish.

(iii) A debating society whose members are each thoroughly prejudiced. As a result of the opposition and balance of these individual prejudices, the society as a whole displays neutrality rather than prejudice (Fricker 2010, pp. 236-239). ${ }^{7}$

Fricker claims that the summativist view can accommodate (i). While the individuals are each characteristically open minded, 'close-mindedness' is a feature of each of them in the context of the church committee because each of them feels under pressure to adopt a close-minded view through, for example, fear of a 'negative reaction by powerful authorities outside the group' (Fricker 2010, p. 237 quoting Lahroodi 2007, p. 288). By contrast (ii), says Fricker, is a counter-example to summativism.

Here the summativist cannot respond by saying that the group feature is to be understood as the sum of the individual features, for the individual features in question (each member's wholehearted commitment qua committee members) are not found at the level of individuals considered independently from the group, for the individuals only have that feature if they are wearing their group-member hat. Some practical identities of individual members are thus intrinsically group-involving, and in such cases there is no lower level of group-independent features to which the higher-level features can be reduced. Any attempted reduction of the group to a sum of uncommitted non-group identified individuals would literally change the subject, and so fail (Fricker 2010, pp. 238-239).

Fricker gives (iii) as an example of a group feature that fails to mirror the motivational and explanatory aspects of individual personal virtues (Fricker 2010, p. 239). Each of the debating society's members is prejudiced, but as it so happens the combination of their biases results in overall neutrality. But Fricker cites a requirement of virtue that the 'good conduct [flowing from or associated with the virtue] is performed because of the good motive or skill'. And the group's neutrality in this example is nothing like this. Rather, insofar as it connects to the skills or motives of the group, it is a 'mere accident' (Fricker 2010, p. 239). ${ }^{8}$ It does not arise from any kind of 'group sensitivity to the demands of' neutrality, as any such sensitivity is wholly absent. 'Neutrality' in the debating society is an effect of the

\footnotetext{
${ }^{7}$ Example (i) follows Lahroodi (2007, p. 288).

${ }^{8}$ Of course the setting up of a debating society in this way may be no 'accident'. The head of a debating society could deliberately select a panel of prejudiced individuals, so as to achieve overall balance (if not quite 'neutrality') and a lively discussion. I take Fricker's point to be that there is no motive to neutrality residing anywhere within that group.
} 
group's members having just the opposite disposition, but virtues are traits which exhibit the good skills or motives by which we name them virtues.

Informed by these examples, Fricker seeks to construct a model of institutional virtue which robustly resists the reduction to an aggregation of individual characteristics as in (i); which rules out 'invisible hand' cases as in (iii); and which captures the motivational or explanatory causal condition of virtue by which the virtuous group activity or attitude happens or arises because of the virtue, the motive or skill. ${ }^{9}$ So Fricker goes for the 'practical identities' model illustrated in the amateur dramatics society example in (ii). In doing so, Fricker adopts the notion of joint commitment from Margaret Gilbert. For Fricker, the joint commitment can be to certain motives (such as compassion or kindness) or to the achievement of certain ends via skills we consider virtues in service of those ends. Joint commitment to perform the skill, apart from any particular motive, is what matters in the latter case. The virtue-as-skill of vigilance is exhibited via the division of labour in a nightwatch team, where each of the members guards their post (one looking east, one looking west, and so on) quite possibly just because each of them is well trained to do so. In this example the joint commitment is not necessarily to a motive but rather to the end of vigilance, 'to be construed as a sheer collective skill, with no collective motivational implications' (Fricker 2010, p. 243).

Fricker aims for a characterization of group virtues that works for both the motive and skill senses of virtue, and both the non-collectivist 'clusters of individuals' and the collectivist senses of 'group'. In respect of both senses of virtue and the first sense of group, her account is successful and informative. ${ }^{10}$ As I argue next, however, it falls short of providing a satisfactory collectivist model for group virtues. Thus it fails to meet what Fricker herself sees as 'the relevant philosophical challenge' (Fricker 2010, p. 235).

\section{Problems with Fricker's Account}

Fricker's strategy for establishing group virtue in the collectivist sense is to argue that the joint commitment to a motive or an end is a distinctly collective attribute. There are two strands to her approach here. One of these rests on a claim of irreducibility. Group members' joint commitment to a motive or end can be a virtue, even though not all or even any of them qua non-group bound individuals possess such commitment. As a result we have, for Fricker, an irreducibly collective virtue. Another related claim is that joint commitments are distinctly collective because the practical identities under which members make such commitments are intrinsically group-involving. I will take these two lines of argument in turn.

\footnotetext{
${ }^{9}$ Groups could have valuable features that entirely lack the 'because of' condition. Cohesion, for example, may be a valuable feature of a community, but also be completely motivationally or explanatorily inert. It may be never be a feature because of which the community does anything or holds attitudes.

${ }^{10}$ For a different critique of Fricker's paper see Ziv (2012).
} 


\section{The Irreducibility Strategy}

Fricker employs two senses of 'individual' in her discussion, one in which the individual wears her group-hat and one in which she does not. The problem is that she shows the irreducibility of a group of hat-wearers' motives to a group of non-hat wearers' motives, but then takes this to show the irreducibility of the group motive per se. To elucidate, Fricker claims that '[a]ny attempted reduction of the group to a sum of uncommitted non-group identified individuals [in the non-hat wearing sense] would literally change the subject, and so fail' (Fricker 2010, p. 239). This is true. It would fail precisely because it attempts to reduce the group motive to things to which it is causally and explanatorily unrelated, namely the individuals' non-hat wearing and non-group oriented motives. When detached from their roles as committee members or night guards, individuals' indifference to their committee's preservation or night-watch duties is irrelevant to their group-concerning joint commitment.

So, the group commitment cannot boil down to features of individual members considered apart from their status as, for example, committee members. Instead, it can rightly be analysed into the role-relevant commitments of the same individuals in their roles qua committee members. The plausible reduction here is from the group's commitment to the motive or end (at the higher level) to each individual's commitment to the motive or end qua group member (at the lower level). As Fricker herself explains, it is the latter, hat-wearing, role which an individual must distinguish and adopt when making the relevant joint commitment. Each individual may have 'conflicting feelings and commitments but it is nonetheless clear to each member which among their various attitudes and motivations they are obliged to bring to bear in any given context, depending on which hat they are wearing' (Fricker 2010, p. 238). Thus the individual amateur dramatists, or enough of them, ${ }^{11}$ each act and think under the description 'society member' when joining together in commitment to their society's preservation. And the vigilance of the night-watch team consists in individuals, as members, committing to the end of vigilance qua night-watch members under specific descriptions of that practical identity. In each example it is individuals who make their group-oriented joint commitments albeit crucially, and only, when wearing their 'hats' which comprise their institutional social role and its obligations. ${ }^{12}$ The resulting joint commitment, in this way, comprises individuals' commitments. The amateur dramatics society's commitment to its preservation and the night-watch team's vigilance are certainly valuable features of those groups. But they fail as examples of irreducibly collective virtues.

\section{Joint Commitment as Intrinsically Group-Involving}

Fricker's other line of defence is that group virtues, as joint commitments, intrinsically involve distinctly social entities. When the group members together put

\footnotetext{
11 Fricker deals with the phenomena of 'passengers' and 'stowaways' as possible members who may not actively jointly commit (Fricker 2010, pp. 240-248).

12 See Hardimon (1994).
} 
forth their commitments, their commitment is to something intrinsically social. The amateur dramatists, for example, are motivated to preserve something obviously social, namely the amateur dramatics society. 'Society' is intrinsic to the amateur dramatists' joint commitment and, for Fricker, sufficient to render that commitment a group virtue in the collectivist sense. What pulls the 'intrinsically groupinvolving' commitment from its membership is the intrinsically social entity of the institution.

We should, however, be careful not to infer the collectivity of a joint commitment from the intrinsically social quality of the thing to which it commits. In itself, a commitment's intrinsically involving a distinctly social entity neither makes that commitment intrinsically social nor dissolves its basis in individuals. To see this, we can grant that there are some social phenomena which are (a) not analysable or explicable in terms of individual phenomena, and which are (b) needed for a full description of some motives and actions of some individual(s). Each member of an athletics relay team, for example, could not commit to competing in their event without taking into account some such wholly social phenomena. These include the concepts of 'competitive sport' and 'team event', as well as the social institution of competitive athletics in which to compete, the relay event and its rules and practices, and a particular team for each competitor to join. Yet none of this dis-individuates each team member's commitment(s) to join with a team (or that particular team), to excel at the relay event or at sport in general, or to run and pass the baton on to a fellow team-member, and so on. Each runner's commitment to instantiating team-spirit, for example, can be individuated in just this way even if 'team-spirit' may itself be attributable only to 'team' as a collective entity. It is in this way that Fricker's examples of joint commitments are most intelligible, as individuals' commitments combining under certain group and institutional requirements.

A defender of Fricker's position might respond that this objection misses an important point. Joint commitments, they might say, comprise not only a number of individuals each committing to pursue a goal such as vigilance, but also their committing to unify in order to do so: to further that goal together as one. They might add that it is precisely in such concert that individuals form the plural subject $^{13}$ which can collectively bear and evince the virtue. So, the night watch embodies the virtue of vigilance not only through each individual members' commitment to the end of vigilance, but also by virtue of their commitment to each other to pursue vigilance as a collective.

Granted. Still, however, the problem for collectivism persists in light of the explanatory and motivational requirements of substantive virtues. As Fricker persuasively argues, for vigilant activity to be an instance of virtue, the activity would have to happen non-accidentally because of that virtue. And as I have argued, night-watch vigilance meets the 'because of' condition by being a group feature to which individual members direct—and should direct—-their commitment. This

\footnotetext{
13 The term 'plural subject', as well as the notion of joint commitment, is adopted from Gilbert: '[f]or persons $\mathrm{A}$ and $\mathrm{B}$ and psychological attribute $\mathrm{X}, \mathrm{A}$ and $\mathrm{B}$ form a plural subject if and only if $\mathrm{A}$ and $\mathrm{B}$ are jointly committed to X-ing as a body, or, if you like, as a single person' (Gilbert 1994, p. 245; see also Gilbert 1996, p. 183).
} 
remains the case even on the understanding that a joint commitment is not only from each member to the same end, but also from each member to the others. Institutionally determined night-watch obligations elicit and specify the commitment to the end of team-vigilance ('this is what we do'), while the necessity of team-working for achieving that end requires that the commitment is a joint one ('this is how we do it'). The problem in accounting for this feature as a substantive virtue and in the collectivist sense remains. For such joint commitment does not bestow the group — the plural subject—with a virtue qua trait which explains or motivates its conduct. Rather, as highlighted in the examples that Fricker herself uses, the relevant group conduct arises from certain group directed and elicited motivations of individual members. That is, group vigilance is best understood as happening because of - in Fricker's sense-institutionally elicited joint commitments by individuals to the relevant end or motive.

To be sure, valuable-perhaps indispensable - qualities of groups such as night watch vigilance, concern for an amateur dramatics society's preservation, or athletic team spirit, may be manifest only by a group to which individuals are appropriately and jointly committed. Yet these qualities are not themselves attitudes or motives of the group that are distinct from those of individual members, and so they are not substantive virtues that are predicated of the group in the collectivist sense. On the contrary they comprise, or are 'put there', by appropriately group-oriented individuals. More positively then, what comes to light in Fricker's examples is the constitutive mutual relation between a) institutionally determined group ends and b) group-members' virtuous motivations given those ends. This point seems just as important for traditional individually focused virtue theories as for group virtue theories, and I will say a bit more about this in the final section of this paper. Next, I turn to a very different account of the moral virtues of groups.

\section{Second Account: Group Moral Virtues}

In 'The Idea of Group Moral Virtue', Donald Beggs (2003) argues that some groups are moral agents which 'can have virtues in a primary moral sense' (Beggs 2003, p. 458). In contrast to Fricker's institutional account, Beggs looks at the subject of less formally structured associations. Reflecting on Aristotle, he sketches the collectivist basis of his view:

[C]ollective predication of moral dispositions is how we can best understand Aristotle's claim [...] that a polis can itself be virtuous. For Aristotle a polis is not an aggregate or mere voluntary association of citizens, just as the hand is not an aggregate of fingers and whatnot. Since the city is in some sense a whole, then its acts can be morally evaluated. But crucially, once it has, in this sense, become an agent, its acts arise from its own dispositions, and these enable us to explain and evaluate those acts independently of the acts and dispositions of each citizen (Beggs 2003, p. 459).

Echoing Fricker's non-summativism, Beggs says that a property of a group is distributively predicated just in case it is a property of individual members, whereas 
a property of a group is collectively predicated of the group without necessarily being predicated of any member. Beggs draws this distinction in support of the idea that a group, as an agent distinct from individual agents, can bear collectively predicated moral virtues. For a group's moral agency, Beggs cites 'deliberative practices/decision procedures' and 'solidarity' as a pair of singly necessary and jointly sufficient conditions. To take the second of his conditions first, Quoting Larry May, Beggs describes solidarity as 'a set of "relations which binds the [...] group together"' (Beggs 2003, p. 463; May 1987, p. 74), on which it is a "way of being interested in what is happening to one's fellow group members" (Beggs 2003, p. 463; May 1987, p. 40). The other necessary condition for moral agencythe presence of decision procedures and practices - is on Beggs's account closely analogous to a condition of deliberation in individual moral agents. Taking these conditions together, '[G]roups constituted by solidarity without decision practices/ procedures are "blind", and groups constituted by decision practices/procedures without solidarity are "empty" (Beggs 2003, p. 463).

Beggs again turns to Aristotle for an account of how a virtue can be collectively predicated of a group agent. In an individual agent, the inculcation of virtue as a disposition is dependent on their repeating the action, thereby instilling the disposition, habituating it in a way that is not forgettable in the way that, for example, cognition of facts is. Certain groups, through internal deliberation and practices, have a close analogue to individuals in what, following Bordieu, Beggs identifies as habitus. Where for Aristotle the individual's disposition, hexis, is developed by the individual repeatedly practising, habitus is a public system of practices, "principles which generate and organize practices and representations that can be objectively adapted to their outcomes without presupposing a conscious aiming at ends or an express mastery of the operations necessary in order to attain them' (Beggs 2003, p. 465; Bourdieu 1990, p. 53). 'Practice' is here understood here not as individual acts of practising, which are 'properly predicated of individuals' but instead as 'the social grammars (the types) that an individual agent's actions manifest (the tokens) through their own styles, their own inflections'. The analogue then, is that 'disposition is to individual as practice [in the 'type' sense] is to group' (Beggs 2003, p. 466). Practices, so understood, are the group analogues to individual dispositions. Accordingly for Beggs, group virtues need not be connected to any aims external to the group agent, as 'some groups do not have defined goals but may still have moral virtues, and still others may have virtues independently of the goals they may have' (Beggs 2003, p. 467). ${ }^{14}$

How might all this play out in an example of a social group? An informal 'quilting group' of elderly middle class women regularly does charity work but is not a charitable organization as such. It develops the collective civic virtue of 'radical tolerance', by which the group decides collectively to raise funds for inner city AIDS sufferers in the following way:

\footnotetext{
14 This condition appears to be a corollary of the kind of solidarity Beggs sees as necessary for group moral agency. This kind of solidarity is, for Beggs, inward looking and not outward looking, consisting in mutual recognition of each other as fellow group members rather than, for example, the instrumental solidarity that Trade Union comrades might have for the sake of a successful strike or for the wider interests of the working class.
} 
[The group] could have decided to try to help people much more like the group's members, say, at the expensive hospice just outside of town. But it didn't. Perhaps under the influence of such factors as famous personalities and Oscar night red ribbons, it came to the conclusion that helping people quite different from its members would be more satisfying than helping people rather more like its members. Now, say that this complex of supportive actions was successful and came to be repeated. Say it became a normal part of the group's functioning without ever becoming politicized, that is, without explicitly orienting its actions and attitudes toward ongoing policy issues. This then would count, I think, as the group's moral virtue of radical tolerance. And it can remain true that none of the members has acquired the sentiments that would sufficiently incline her to such actions; no member of the group has that virtue (Beggs 2003, p. 468).

The group has remained a number of elderly middle class women that gives to charity whilst undergoing a change in its moral character as a group moral agent. It has, in this example, done so wholly independently of the moral character or attitudes of its members. It has acquired the virtue of radical tolerance without any member of the group themselves acquiring or evincing any such disposition. Indeed it has done this without anyone having directed any actions or attitudes towards a policy, purpose or sentiment related to radical tolerance. This then, is collective and non-individual predication of a group virtue par excellence.

I will argue in the next sub-section that such collectively predicated group features fail as candidates for substantive virtues. Beforehand, it is worth getting clear about the heavy work that collective predication is doing in Beggs's account. In the example, Beggs articulates conditions under which a virtue arises from a group of individuals none of whom possesses or is aware of it. Clearly, for Beggs, this exclusively collective, non-distributive, predication of a virtue is sufficient for its status as group virtue. But it is also necessary for distinguishing Beggs's particular view of group virtues as collectivist par excellence. The weight of exclusively collective predication is in it purportedly instantiating a virtue in the group as an entity in its own right, without having to locate that virtue in individuals. As such it is the very basis on which the group feature such as radical tolerance can really be numerically distinct from any similar motives, sentiments, considerations or attitudes, of the group's members. It is precisely how 'acts' of a group agent such as the Polis can supposedly 'arise from its own dispositions [which] enable us to explain and evaluate those acts independently of the acts and dispositions of each citizen'. Consider the difficulty of coherently defending collectivism about virtues without this bulwark of exclusively collective predication. To accommodate causally relevant contributions of individuals would at least seriously risk muddying the collectivist waters, if not undermining the position entirely. $^{15}$

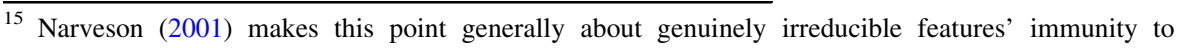
individual predication in relation to collective responsibility.
} 


\section{Problems with Beggs's Account}

To test the plausibility of collectively predicated features as virtues, I start with a commonplace (though as we will see, contestable) view about virtues of character. That view holds that in order to be a substantive virtue (or vice) of character, the value (or lack of value) of a character trait must sometimes, in some way, figure in the deliberation and attitudes of the agent who has, or aspires to have, that character. This is to posit only some minimal conditions for virtue, comprising the agent's (defeasible) capacity to reflect on the value of that virtue and consider reasons for inculcating it. Jane may think that tolerance is a virtue and that therefore she has reason to develop a tolerant disposition and, where possible, act tolerantly. But she could also just reflect approvingly on her own tolerant conduct without individuating a disposition to tolerance or naming it as a virtue. One can just come to realise that in acting a certain way one acts well and is praiseworthy, and that in doing so one is developing or affirming oneself as a good or improving person. Similarly we may recognize some of our own traits as vices, or as things about ourselves we disvalue or regret and so want to expunge or curb. Insofar as we think that a virtue is a valuable disposition worthy of development and praise, we think there is good reason for an aspiring good person to consider it as such in selfreflection. To the extent that we hold moral persons as capable of moral or epistemic self-development, we think that agents can and should value and promote certain traits and extirpate others. This idea is an important, perhaps indispensable, part of the putative concepts of virtue and vice.

If it is true that some such capability for evaluative reflection is necessary for a substantive virtue of character, then Beggs's account needs to provide some account of that capability in his group agent. As we have seen, Beggs is careful to make certain group features analogous to the reflective capacities of individual agents. The public system of decision procedures and practices-habitus - is analogous to hexis in individuals. Practices here are structural features of the group, as its 'social grammars' and habituated interactions. For Beggs, it is these quasi-psychological structures that can instantiate a socio-political virtue such as radical tolerance without the virtue figuring in the psychologies of, or interactions between, individual practisers. Particular interactions may be motivated by individuals' desires for satisfaction or be influenced by Oscar night celebrations. Yet the practices and procedures arising from these interactions emerge as something else, namely collectively predicated radical tolerance. Here then, is what might seem to be an account of just such a reflective capability in the group agent.

Yet it is difficult to see how the group agent could deliberate about or reflect on the value of radical tolerance, or how its value could figure in the group agent's motives and attitudes. For in Beggs's scenario, neither radical tolerance nor its value are objects of reflection at all. The 'complex of [individuals'] supportive actions' over time forms part of what the collective tends to do as a practice, and in this sense the group can be said to have developed a tendency to radical tolerance. As a group agent, however, it does not appear to have the capacity to evaluate that tendency and enhance that tendency because of its value. Practices do not themselves reflectively evaluate on anything, let alone possess motives or values. 
Only agents do or possess these kinds of things. But as candidates for which agent is to reflect on, value, and incorporate radical tolerance, Beggs rules out individuals, yet fails to show how the group-agent is capable of doing so independently of those individuals. Beggs's account, then, is implausible to the extent that it falls short of meeting the reflective evaluation condition.

A proponent of Beggs's position could, however, deny that this condition is necessary for virtue. A direct strategy here would be for them to adopt the instrumentalist view of virtue defended by Julia Driver (2001). On this view a trait is valuable, and thus a virtue, when and because it tends to have good effects. As what matters for the instrumentalist is just 'the external state of affairs or the consequences produced by the character traits'(Driver 2001, p. 49), no such agent internal reflection on or sensitivity to the value of such traits are necessary for their status as virtues. If Beggs's collectivism about group agents were allied with Driver's instrumentalism about virtues, the quilting group's radical tolerance would be a virtue solely because of its likely valuable effects in the world. Radical tolerance, for example, would most plausibly tend to effect social justice, and this would be true regardless of anything about the inner world of the group agent. The virtue's value is just what it tends to do, so to speak.

With the instrumentalist modification, then, Begg's collectivism can avoid the demand for reflective evaluation in his group agent. This modified position, however, raises its own problem. To explain, and argue that it supports a rejection of collectivism, I will consider two claims. The first is that a virtue's value provides good prima facie reasons for it to be actively cultivated. In the present instrumentalist context, if tolerance is valuable because of its effects, then there are such good reasons for tolerance to be nurtured and sustained in pursuit of producing those effects. The second claim, in the group context, is that in order best to nurture and sustain some valuable group feature, at least some individual group members should see, and be moved to act on, those reasons.

The first claim is particularly difficult for the instrumentalist about virtue to reject. If someone holds that a trait is a virtue because it is an instrument to valuable effects in the world, then it would seem incoherent for them to deny that we have good reasons to look after and develop that instrument. Those reasons appear no less pertinent for the instrumentalist about virtues who wants also to be a collectivist. Many kinds of social groups tend to have more significant effects in the world than most of us do qua individuals. The second claim could more easily be rejected by the collectivist. For it is conceivable that some instrumentally valuable group feature could be cultivated in a group without its coming to figure in any individual member's intentions or attitudes. Radical tolerance could be nurtured intentionally by agents outside of the quilting group. Alternatively or also, it could just develop without the direct or intentional involvement of any agents, but under wider social influences such as prevailing economic or political conditions, for example. Some pattern of radically tolerant activity or behaviour could, in these ways, develop in the group without the conscious influence of any group member. Here we could have the development of an enduring, collectively predicated and instrumentally valuable group feature. Seemingly, it could therefore count as a group virtue. 
At this point, though, the role of the group agent becomes so diminished as to become indiscernible. Beggs rightly characterises what I have called a substantive virtue - a trait of character - as something that has to be rooted in agency, hence the need in his account to establish a group moral agent (Beggs 2003, pp. 462-463). However we might value a virtue, it seems part of our concept of a character trait, rather than a tick or compulsion, that it becomes a disposition in favour of acting intentionally for certain reasons and not others. ${ }^{16}$ Substantive virtues thus require agency. And the real problem with an instrumentally valuable group feature is that it has no need for agency. Where a group can have some such feature, neither its presence nor its development requires the prior presence or instantiation of a collective agent. Agents external to the group's members, for example, could cultivate instrumentally and politically valuable group features, where this might mean promoting deliberative procedures and practices that best instantiate those features. Here, though, those structural features of the group, which Beggs sees as part of the group's agency, could just themselves be purely instrumental in manifesting the valuable effects of group activity. This seems perfectly conceivable without first finding, or building into the picture, the group agency that is needed to bear a substantive virtue. Such features thus seem unlikely candidates as collective substantive virtues that can only properly be predicated of agents. With the instrumentalist modification, collectivism can avoid the demands of reflective evaluation, but at the cost of making the collective agent - the supposed possessor of the genuine group virtue-all but redundant.

The instrumentalist take also raises a normative question for collectivism about virtues. If a group feature is instrumentally valuable, then we should ask how best to look after and wield the instrument so as to effect its value. In answer to which there would seem no good reason to maintain the collectivist view. Beggs himself expresses the hope that "virtue ethics can escape its thraldom to the soul-in the figure of the person' (Beggs 2003, p. 458) and adds the promissory claim that '[g]roup virtues are a distinctive yet heretofore unrecognized form which, through intermediate associations, moral agents can collectively develop and act on conceptions of the good while preserving pluralism and developing civil society' (Beggs 2003, p. 470). Yet, if a group virtue ethics or political theory is to be applied in this way, then which agents are to recognize and develop these virtues? How would group virtues best be propagated within or beyond their subject groups, if not by involving at least some individual members' acquisition or conscious cultivation of that virtue? Why not drop the collectivist constraint, and allow that (at least some of) the individual agents within the relevant group would be among those best placed intentionally to advance these virtues and their effects?

In response to this clutch of rhetorical questions, if some valuable feature is to be developed in a group then there appear to be no grounds on which to deny that individual agents - including relevant group members-should do the developing. Individuals in those groups would seem well placed to do this, by their actions and their advancing arguments about which of their group's features should be deemed

\footnotetext{
16 Notice that some quite strong, valuable and reliable dispositions of some kind can of course be developed in some putative non-rational beings, as for example when handlers train rescue or guide dogs.
} 
virtues or vices and why; about how these virtues should be developed and encouraged; or about the extent to which group activities would be right or wrong by virtue of their manifesting virtue or vice, and so on.

Beggs's account shows ways in which groups can possess some features collectively. But it faces difficulties with establishing substantive group virtues on this basis. The group appears to lack a reflective and self-evaluative capacity that is, on one common view, needed for virtue. Alternatively, the group without this capacity can possess a valuable feature, but in that case can do without the agency required for substantive virtue. Insofar as some group feature can be genuinely collective, possessed by the group in its own right, it has little conceptual or normative traction as a substantive virtue.

\section{Conclusions: Towards a Non-collectivist Account of Social Group Virtues}

I contend that the limitations of both the collectivist accounts discussed support a different, non-collectivist interpretation of social groups and virtues, as do some of their positive insights.

To see this, let us first return to Fricker's third way of speaking of institutionalized groups, which earlier I left aside. In this manner of speaking, virtues are strengths of social institutions rather than virtues of character. Virtues in this sense are such things as rules, practices or procedures which could endure regardless of which particular individuals are part of the group at any time (Fricker 2010 , p. 236). Fricker's insight here is in identifying this constitutive relation between, on one hand, structural group strengths and, on the other hand, groupspecific motives and attitudes of individual agents qua members. Group strengths serve as essential criteria for the appropriate exhibition of virtue by their individual constituents qua members (Swanton 2007). The problem is with Fricker running the two distinct phenomena together and mischaracterising the combination as an instance of collectivist virtue. Aspects of Beggs's account underpin the noncollectivist interpretation in a similar way. His practices and social grammars, as group habitus, are also institutional in the sense of being socially instituted structures, procedures or norms. The main problems in Beggs's view are with his first making these structural group features quasi-psychological features of the group agent, and then trying to show that this group agent can itself sustain a substantive virtue independently of individual members' motives or attitudes.

Taking into account these insights and problems, an alternative non-collectivist view can recognize the value of social structural features, as can the collectivist view. Unlike collectivism, it distinguishes these features from group-specific virtues which are properties of individual members. It also recognizes the constitutive relation between those social features and those virtues, without problematically seeking to run the two together. Different kinds of groups can have variously valuable features which serve as criteria for what counts as appropriate groupspecific virtuous motives and actions. Some groups may have specific valuable functions by dint of which the virtuous motive will be to fulfil that function (night 
watch vigilance). Some valuable features of other groups may not be linked directly to a specified or primary function, but nonetheless be beneficial to the group qua that kind of group (relay team-spirit). Others may not be linked to group functions at all but nonetheless be socially beneficial, giving us good reasons to nurture them in that group (quilting group radical tolerance). And others still may be valuable in more than one, or all, of these ways (mountain rescue-team courage). In each of these cases, valuable group features can serve to elicit group-specific social virtues: appropriately group oriented attitudes, motives and actions of group members. This, it seems to me, is the right way of understanding virtues in the context of social groups, and it could work better than the collectivist view in a socially enriched normative virtue theory. If we are to formulate a virtue theory that can tell us something about which practices, conduct or policies can and should be instantiated in groups and manifest in the world, we should forget about trying to establish collective substantive virtues. Instead, we would do better to look at which features a particular kind of group should have, and at which relevant motives and attitudes an individual should possess qua member of that group. Just as importantly, we should study the ways in which these things interact with each other.

For all this, it might be said that the concept of collective virtue could still usefully figure in good explanations of certain social phenomena, and in normative theories of social groups. So, even if it is false or highly unlikely that groups can literally possess virtues, the collectivist view could provide a useful methodological model for looking at certain kind of group behaviours, or at group contextual norms, and the social dimensions of individual's virtues and vices, for example. I suggest, in response, that we have further reason to be cautious about adopting the collectivist point of view in this way.

The dangers with adopting the collectivist position might be best exemplified by a case of a group vice. Suppose that a certain group of individuals is charged with having sexist tendencies. In order to assess this claim and, if true, to begin eradicating the sexism, we would ask how sexism is present in the group and how it tends to be manifest. Digging further down, we would rightly ask which aspects of the group's sexism are properly attributable to particular members, past or present, and which to its structural features. If we were to find examples of the latter, such as sexist rules, conventions, cultures or practices, then we may need to establish which if any have preceded and survived particular members, and which if any are promulgated by a particular cohort of current (perhaps especially influential) members. Supposing now that some members have at some point instantiated or sustained sexist structures, it may then be important to find, where possible, whether any member(s) actively $\operatorname{seek}(\mathrm{s})$ to perpetuate sexist structures. By contrast there may be some who resist and challenge sexist structures or the sexist attitudes of its members (and may thereby be rightly deemed anti-sexist, perhaps even courageously so in the face of peer pressure). Other group members may tacitly encourage or condone sexism by turning a blind eye. Of those members we can ask whether their acquiescence is only or mostly under the influence of sexist group structures and whether some members harbour sexist attitudes prior to the group context. Such attitudes may explain and motivate blind-eye turning, and they may play a part in upholding sexist structures. 
The list could go on, and its being non-exhaustive underlines both the complex relation of individual and group features and the anti-collectivist point of the example. As we have seen, the bite of the collectivist view is that there can be virtues and vices of groups which are attributable, as traits, to the group as a whole and in its own right. I have argued that collectivism about virtues is unsuccessful because, in essence, it too readily elides social structural phenomena and personal traits. That conclusion, if true, would seem true of virtue collectivism whichever way it is employed. Approaching the complex sources and loci of the group's sexism using a collectivist model would appear to bring no more explanatory or normative power than a non-collectivist approach. More perniciously it would bring risks of descriptive and prescriptive failure due to blurring things that are to be explained or justified. One risk is of misattributing agent traits such as sexism to non-agents. Another is lumping together individual and super-individual phenomena which need to be separated in order to identify, judge and-we might hopeultimately quash the group's sexism.

The sexism example illustrates a fear that through a collectivist virtue lens we might struggle to see the trees for the wood. This should not, however, lead us to favour an individualist focus on virtues that struggles to see the wood for the trees. In assessing and ultimately rejecting the collectivist position on group virtues, I hope to have shown that there are valuable (or dis-valuable) features of social groups which figure appropriately in the individual's practical reasoning and virtuous motivations qua member of that group. Theorists of individuals' virtues should heed this lesson to the extent that their theories must accommodate the obligations and norms of social roles (Oakley and Cocking 2001; MacIntyre 2006; Hursthouse 2007; Swanton 2007). That is surely a significant extent, for such obligations and norms are born by individuals but determined by social institutions (Dahrendorf 1970).

Finally, I suggest that this last point generalizes beyond virtue theory. We need not clamour towards prioritizing either social or individual phenomena when first seeking to explain the co-existence of both. As part of a persuasive interpretation of Hegel's social philosophy, Kenneth Westphal has summed up the general point, which anyone tempted in either direction would do well to consider:

There are no individuals - no social practitioners - without social practices, and vice versa, there are no social practices without social practitioners, that is, without individuals who learn, participate in, perpetuate, and who modify social practices as needed to meet their changing needs, aims, and circumstances (including procedures and information). [I]ndividual human beings and the social groups to which they belong are mutually interdependent for their existence and characteristics (Westphal 2010, pp. 168-169).

Acknowledgments For helpful comments or discussions on earlier drafts of this paper, I would like to thank Alex Barber, Cristina Chimisso, Sophie-Grace Chappell, Sarah Pawlett-Jackson, Carolyn Price, Christopher Bennett, Robert Stern and two anonymous referees at Res Publica. 
Open Access This article is distributed under the terms of the Creative Commons Attribution 4.0 International License (http://creativecommons.org/licenses/by/4.0/), which permits unrestricted use, distribution, and reproduction in any medium, provided you give appropriate credit to the original author(s) and the source, provide a link to the Creative Commons license, and indicate if changes were made.

\section{References}

Beggs, Donald. 2003. The idea of group moral virtue. Journal of Social Philosophy 34: 457-474.

Bourdieu, Pierre. 1990. The logic of practice. New York, NY: Cambridge University Press.

Dahrendorf, Ralf. 1970. Homo socioloigicus: on the history, significance and limits of the category of social role'. In Essays in the theory of society. London: Routledge \& Kegan Paul.

Driver, Julia. 2001. Uneasy virtue. Cambridge: Cambridge University Press.

French, Peter. 1979. The corporation as a moral person. American Philosophical Quarterly 16: 207-215.

Fricker, Miranda. 2010. Can there be institutional virtues? In Oxford studies in epistemology, social epistemology, ed. Tamar Szabó Gendler, and John Hawthorne, 235-252. Oxford: Oxford University Press.

Gilbert, Margaret. 1994. Remarks on collective belief. In Socializing epistemology, ed. Frederick M. Schmitt, 235-256. Lanham: Rowman and Littlefield.

Gilbert, Margaret. 1996. Living together: Rationality, sociality, and obligation. Lanham: Rowman and Littlefield.

Graham, Keith. 2002. Practical reasoning in a social world. Cambridge: Cambridge University Press.

Hardimon, Michael O. 1994. Role obligations. Journal of Philosophy. 9: 333-363.

Huebner, Bryce. 2011. Genuinely collective emotions. European Journal for Philosophy of Science 1: 89-118.

Hursthouse, Rosalind. 2007. Two ways of doing the right thing. In Virtue jurisprudence, ed. Colin Farrelly, and Lawrence B. Solum, 236-255. Hampshire: Palgrave MacMillan.

Isaacs, Tracy. 2006. Collective moral responsibility and collective intention. Midwest Studies in Philosophy 30: 59-73.

Lahroodi, Reza. 2007. Collective epistemic virtues. Social Epistemology 21: 281-297.

MacIntyre, Alasdair. 2006. Social structures and their threat to moral agency. In Ethics and politics, 236-255. Cambridge: Cambridge University Press.

May, Larry. 1987. The morality of groups: Collective responsibility, group based harm, and corporate rights. Notre Dame, IN: University of Notre Dame Press.

Miller, Seamus, and Pekka Mäkelä. 2005. The collectivist approach to moral responsibility. Metaphilosophy 36: 634-651.

Narveson, Jan. 2001. Collective responsibility. The Journal of Ethics 6: 179-198.

Oakley, Justin, and Dean Cocking. 2001. Virtue ethics and professional roles. Cambridge: Cambridge University Press.

Sandin, Per. 2007. Collective military virtues. Journal of Military Ethics 6: 303-314.

Sheehy, Paul. 2007. Blaming them. Journal of Social Philosophy 36: 428-441.

Slote, Michael. 2001. Morals from motives. Oxford: Oxford University Press.

Smith, Michael D. 1982. The virtuous organization. Journal of Medicine and Philosophy 7: 31-42.

Swanton, Christine. 2007. Virtue ethics, role ethics, and business ethics. In Working virtue, ed. Rebecca L. Walker, and Philip J. Ivanhoe, 207-224. Oxford: Oxford University Press.

Westphal, Kenneth. 2010. Hegel. In The routledge companion to ethics, ed. John Skorupski, 168-181. Oxford: Routledge.

Zagzebski, Linda. 2008. Virtues of the mind: An inquiry into the nature of virtue and the ethical foundation of knowledge. Cambridge: Cambridge University Press.

Ziv, Anita Konzelmann. 2012. Institutional virtue: How consensus matters. Philosophical Studies 161: 87-96. 